\title{
Adult colo-colonic intussusception
}

\author{
N. Abbes Orabi · H. M. Paterson · A. Kartheuser
}

Received: 9 November 2009/Accepted: 4 December 2009/Published online: 9 February 2010

(C) Springer-Verlag 2010

A 68-year-old man with no significant medical history was admitted to the emergency department, with abdominal pain and vomiting. Examination revealed severe abdominal distension and rebound tenderness. Abdominal radiography showed distension of the small bowel and colon (Fig. 1). CT scan showed typical images of left colonic intussusception with pericolic infiltration, distension of the small bowel and no evidence of ischaemic changes in the proximal colon (Figs. 2, 3). Surgical exploration revealed left colonic obstruction caused by an intussuscepting tumour (Figs. 4, 5, 6). Oncological resection was performed, with the removal of the inferior mesenteric nodes and primary colorectal anastomosis. The patient made an uncomplicated recovery. Histopathological analysis identified a well-differentiated pT3N0 adenocarcinoma of the colon.

Colo-colonic intussusception is rare in adults. In contrast to children with the condition, a large number of adult patients have an underlying organic lesion. Since many of these lesions are potentially malignant tumours, optimal treatment is to proceed directly to oncological resection without attempting mechanical reduction, in order to avoid perforation and cancer cell seeding.

N. Abbes Orabi · H. M. Paterson · A. Kartheuser $(\bowtie)$ Colorectal Surgery Unit, University Hospital St Luc, Avenue Hippocrate 10, Brussels 1200, Belgium e-mail: alex.kartheuser@uclouvain.be

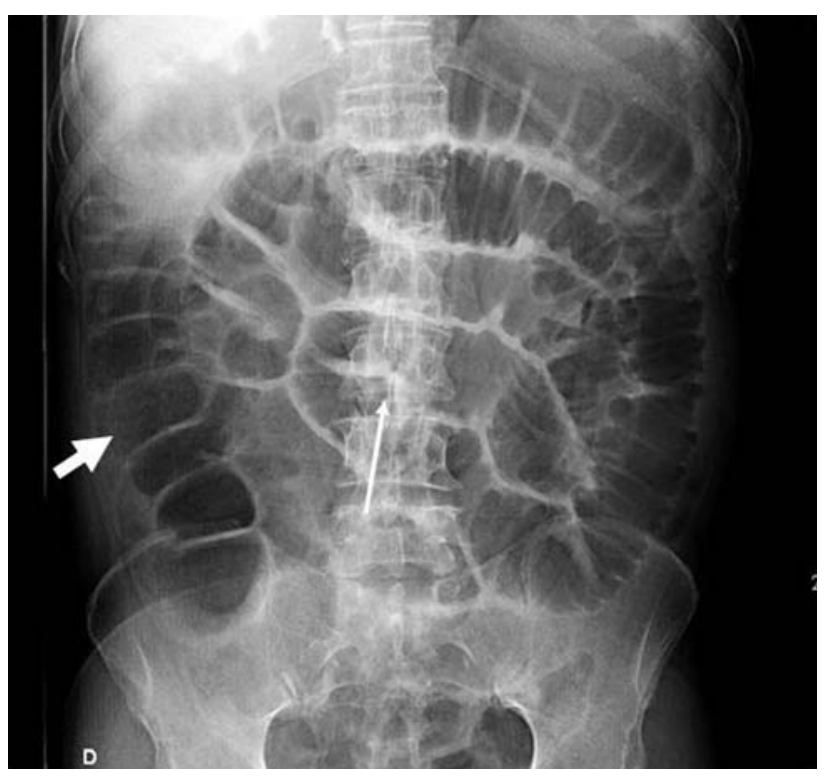

Fig. 1 Abdominal X-ray showing distension of the small bowel (thin arrow) and colon (thick arrow)

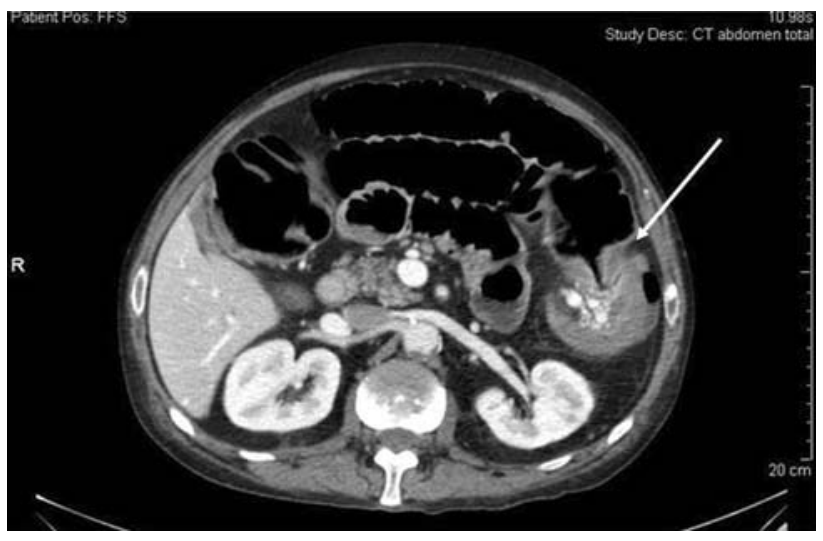

Fig. 2 CT image showing the beginning of the intussusception (arrow) 


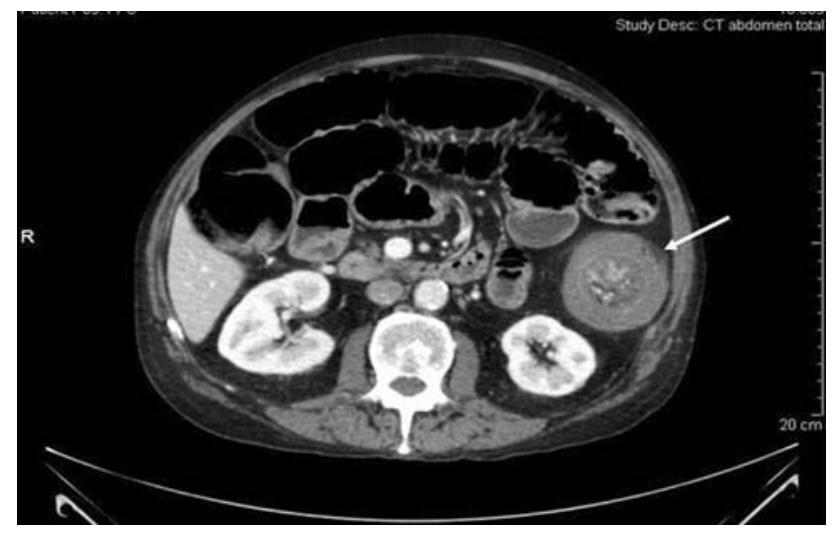

Fig. 3 CT image showing a typical target lesion associated with intussusception (arrow)

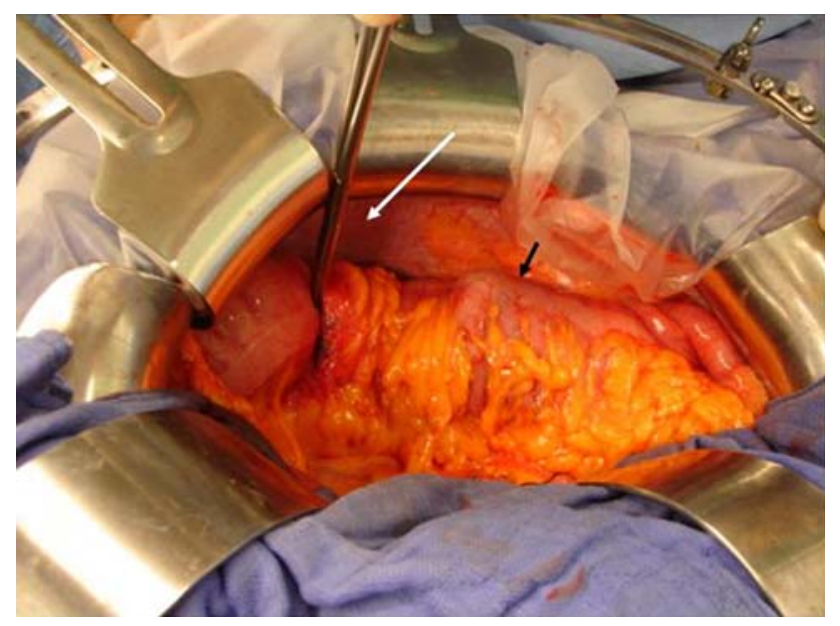

Fig. 4 Peroperative view of left colon (black arrow), and forceps (white arrow) inside the intussusception

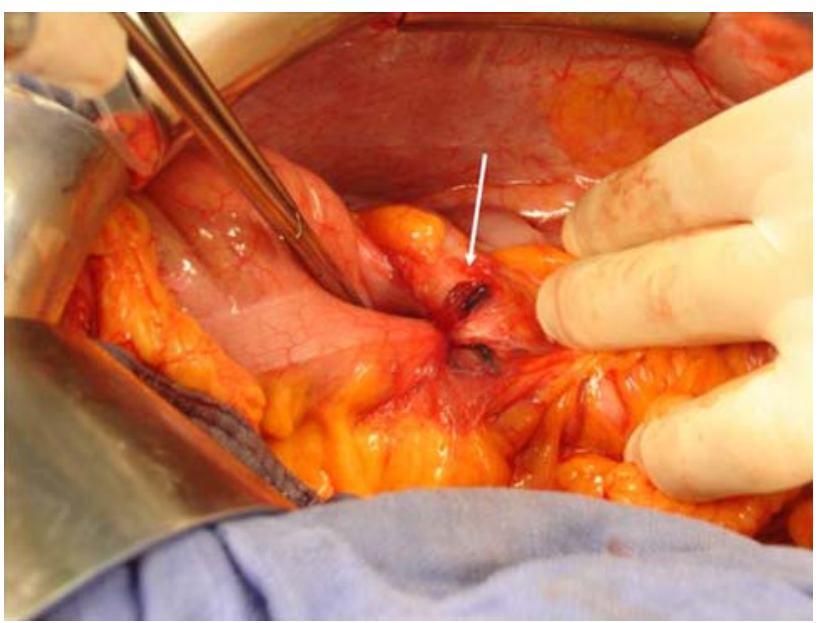

Fig. 5 Peroperative view of the intussusception site (arrow)

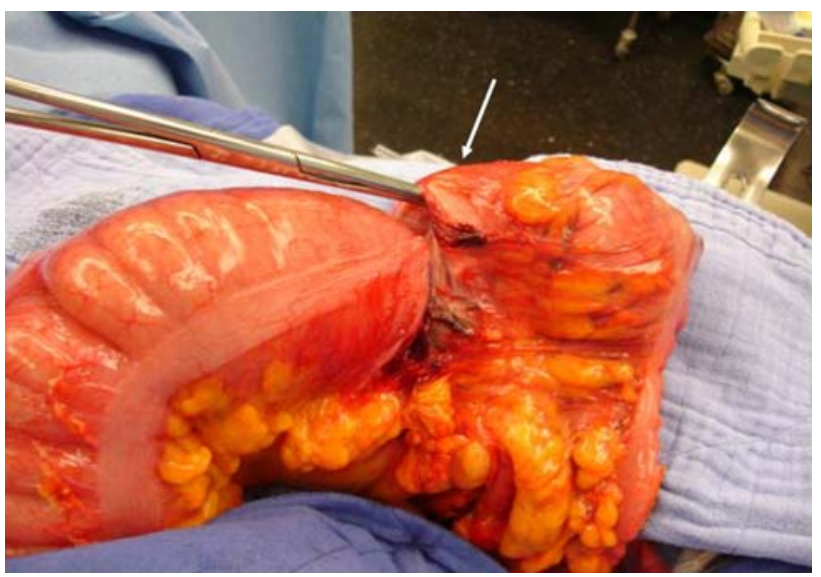

Fig. 6 Peroperative view after mobilization of the left colon with forceps inside the intussusception (arrow) 